University of Nebraska - Lincoln

DigitalCommons@University of Nebraska - Lincoln

\title{
Experimental and Numerical Investigation of the Mechanism of Blast Wave Transmission Through a Surrogate Head
}

\author{
Yi Hua \\ University of Nebraska-Lincoln, yhua3@unl.edu \\ Praveen Akula \\ University of Nebraska-Lincoln, praveenakula20@gmail.com \\ Linxia Gu \\ University of Nebraska-Lincoln, gul@fit.edu \\ Jeff Berg \\ University of Nebraska-Lincoln, jberg@unl.edu \\ Carl A. Nelson \\ University of Nebraska-Lincoln, cnelson5@unl.edu
}

Follow this and additional works at: https://digitalcommons.unl.edu/mechengfacpub

Part of the Acoustics, Dynamics, and Controls Commons, Other Biomedical Engineering and Bioengineering Commons, and the Risk Analysis Commons

Hua, Yi; Akula, Praveen; Gu, Linxia; Berg, Jeff; and Nelson, Carl A., "Experimental and Numerical Investigation of the Mechanism of Blast Wave Transmission Through a Surrogate Head" (2014). Mechanical \& Materials Engineering Faculty Publications. 104.

https://digitalcommons.unl.edu/mechengfacpub/104

This Article is brought to you for free and open access by the Mechanical \& Materials Engineering, Department of at DigitalCommons@University of Nebraska - Lincoln. It has been accepted for inclusion in Mechanical \& Materials Engineering Faculty Publications by an authorized administrator of DigitalCommons@University of Nebraska Lincoln. 


\section{Yi Hua \\ Department of Mechanical and Materials Engineering, \\ University of Nebraska-Lincoln, \\ Lincoln, NE 68588-0656 \\ Praveen Kumar Akula \\ Department of Mechanical and Materials Engineering, \\ University of Nebraska-Lincoln, Lincoln, NE 68588-0656 \\ Experimental and Numerical Investigation of the Mechanism of Blast Wave Transmission Through a Surrogate Head}

\section{Linxia Gu ${ }^{1}$ \\ Department of Mechanical and Materials Engineering, University of Nebraska-Lincoln, Lincoln, NE 68588-0656 \\ Nebraska Center for Materials and Nanoscience, Lincoln, NE 68588-0656 e-mail: Igu@unl.edu}

\author{
Jeff Berg \\ Department of Mechanical \\ and Materials Engineering, \\ University of Nebraska-Lincoln, \\ Lincoln, NE 68588-0656 \\ Carl A. Nelson \\ Department of Mechanical \\ and Materials Engineering, \\ University of Nebraska-Lincoln, \\ Lincoln, NE 68588-0656
}

\begin{abstract}
This work is to develop an experiment-validated numerical model to elucidate the wave transmission mechanisms through a surrogate head under blast loading. Repeated shock tube tests were conducted on a surrogate head, i.e., water-filled polycarbonate shell. Surface strain on the skull simulant and pressure inside the brain simulant were recorded at multiple locations. A numerical model was developed to capture the shock wave propagation within the shock tube and the fluid-structure interaction between the shock wave and the surrogate head. The obtained numerical results were compared with the experimental measurements. The experiment-validated numerical model was then used to further understand the wave transmission mechanisms from the blast to the surrogate head, including the flow field around the head, structural response of the skull simulant, and pressure distributions inside the brain simulant. Results demonstrated that intracranial pressure in the anterior part of the brain simulant was dominated by the direct blast wave propagation, while in the posterior part it was attributed to both direct blast wave propagation and skull flexure, which took effect at a later time. This study served as an exploration of the physics of blast-surrogate interaction and a precursor to a realistic head model. [DOI: 10.1115/1.4026156]
\end{abstract}

Keywords: blast wave, surrogate head, fluid-structure interactions, skull flexure, stress wave

\section{Introduction}

Blast-induced traumatic brain injury (TBI) has been identified as a "signature wound" of modern conflicts such as those in Iraq and Afghanistan [1,2]. A recent report from the Armed Forces Health Surveillance Center (AFHSC) stated that, from 2000 to the fourth quarter of 2011, there have been 233,425 clinically confirmed TBI cases among U.S. service members [3]. Experimental studies using head surrogates, animal models, and post-mortem human specimens combined with computational methods have been used to understand the mechanisms of blast-induced TBI and develop prevention strategies [4-12]. Among these methods, head surrogates are intermediate and less expensive means to identify the detailed blast wave-head interactions as well as the impact of wave transmissions on brain mechanics. Alley et al. [10] conducted blast experiments on a head surrogate consisting of a spherical poly(methyl methacrylate) (PMMA) shell housing synthetic gelatins as brain simulants. Pressure amplification and significant relative displacement were observed at the anterior locations near PMMA/gelatin boundaries, which were attributed to impedance mismatches. Zhu et al. [12] conducted shock tube tests on an egg-shaped head surrogate filled with gels. Static pressures within the shock tube and the surrogate were recorded and a numerical model was developed to assess the effect of elastic modulus of the shell, bulk modulus of the gel, head orientation, and internal sensor location. Although these studies have quantified the mechanical response of a head surrogate under blast load-

\footnotetext{
${ }^{1}$ Corresponding author.

Contributed by the Design Engineering Division of ASME for publication in the Journal of Computational and Nonlinear Dynamics. Manuscript received July 17 , 2013; final manuscript received November 27, 2013; published online February 13, 2014. Assoc. Editor: Carmen M. Lilley.
}

ing in terms of pressure profiles [10,12] and surface strain mapping [10], characterizations of the flow field around the head and mechanisms of load transfer from the blast wave to the brain simulant remain unclear.

In this work, the dynamic response of the water-filled polycarbonate shell under blast loading was investigated using integrated shock tube experiments and numerical simulations. The surface strain on the skull simulant and pressure inside the brain simulant at multiple locations were monitored to validate the numerical model. The validated model was then used to further inspect the mechanisms of blast-wave-surrogate head interactions in terms of flow field around the head, structural response of the skull simulant, and pressure distributions inside the brain simulant.

\section{Materials and Methods}

2.1 Shock Tube Experiments. The shock tube experiments were carried out in a $711 \mathrm{~mm}$ ( $28 \mathrm{in}$.) square shock tube with a total length of $12,319 \mathrm{~mm}$, as shown in Fig. 1. The surrogate head in the test section of the tube was fixed onto a custom-made aluminum clamp. Polycarbonate and water served as skull and brain simulants, respectively, due to their similar material properties listed in Table 1. Water-proof gaskets were used to prevent leakage of water, along with a rubber lining to mitigate hard mechanical coupling between the surrogate and the aluminum clamp. To minimize wave reflections from the shock tube bottom surface, the surrogate head was elevated $65 \mathrm{~mm}$ above the bottom of the shock tube. Pressure histories in the water were measured at three locations using Kulite pressure sensors (Kulite, Basingstoke, U.; model no. LE-080-250 A) as marked in Fig. 2(a). Five Vishay SR4 general-purpose strain gauges (grid resistance $350 \pm 0.3 \% \Omega$; gauge factor $2.09 \pm 0.5 \%$ ) were bonded per Vishay bulletin 


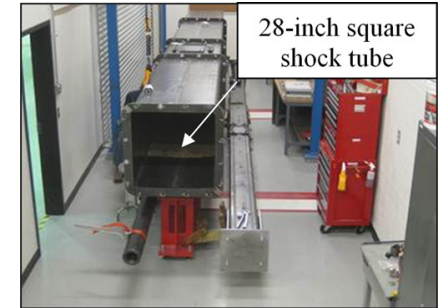

Fig. 1 A $711 \mathrm{~mm}$ (28 in.) square shock tube apparatus

Table 1 Material properties of skull and polycarbonate, brain and water $[34,35]$

\begin{tabular}{|c|c|c|c|c|}
\hline Material & $\begin{array}{c}\text { Density } \\
\rho \\
\left(\mathrm{kg} / \mathrm{m}^{3}\right)\end{array}$ & $\begin{array}{c}\text { Young's } \\
\text { modulus } \\
E \\
(\mathrm{MPa})\end{array}$ & $\begin{array}{c}\text { Bulk } \\
\text { modulus } \\
K \\
(\mathrm{MPa})\end{array}$ & $\begin{array}{c}\text { Acoustic } \\
\text { impedance } \\
Z \\
(\mathrm{MPa} \cdot \mathrm{s} / \mathrm{m})\end{array}$ \\
\hline Skull & 1710 & 5370 & 4820 & $2.1-7.8$ \\
\hline Polycarbonate & 1201 & 2344 & 6297 & 2.7 \\
\hline Brain & 1040 & 0.123 & 2370 & 1.58 \\
\hline Water & 996 & / & 2090 & $1.48-1.54$ \\
\hline
\end{tabular}

B-129-8 onto the surface of the polycarbonate shell and connected to a Wheatstone quarter bridge to measure the longitudinal and transverse strains, as illustrated in Fig. 2(b). The shock wave incident pressure (Fig. 3) was generated by rupturing a stack of six plies of $0.025 \mathrm{~mm}$ thick Mylar membranes. The shape of the incident pressure history was of the Friedlander type, with peak overpressure of $0.13 \mathrm{MPa}$ and positive phase duration of $4.55 \mathrm{~ms}$. Experiments were repeated five times $(N=5)$ to ensure the reliability of the measured results.

2.2 Finite Element Modeling. A three-dimensional model of the surrogate head subjected to blast loading generated inside a shock tube was developed using ABAQUS software (Dassault Systems Simulia Corp., RI), as shown in Fig. 4. The listed homogeneous linear elastic isotropic material properties in Table 1 with a Poisson's ratio of 0.37 were used for the polycarbonate shell with inner diameter of $152.4 \mathrm{~mm}$ and thickness of $1.27 \mathrm{~mm}$. The

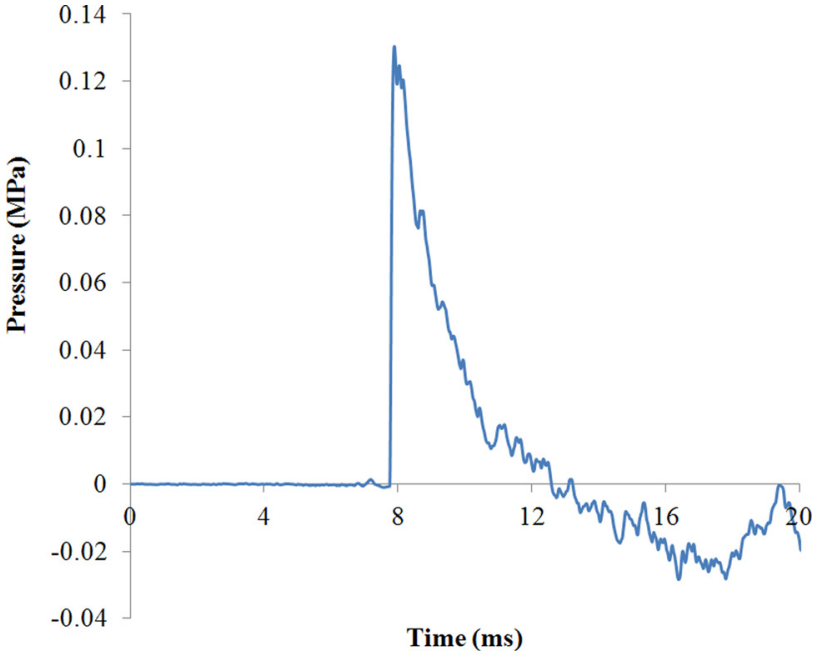

Fig. 3 Experimentally measured Friedlander-type incident pressure history

brain simulant was modeled as an incompressible fluid with the Mie-Grüneisen equation of state (EOS), which related the shock velocity and fluid particle velocity to the pressure inside the water [13]. Air was modeled using an ideal gas EOS since the Mach number of the shock front calculated from our experiments was approximately 1.4 , and the ratio of specific heats did not change drastically at this Mach number. The EOS parameters for both water and air were summarized in Table 2. The aluminum clamp, used to stage the head surrogate inside the shock tube, was assumed as an isotropic material with Young's modulus $E=60 \mathrm{GPa}$, Poisson's ratio $\nu=0.3$, and density $\rho=2700 \mathrm{~kg} / \mathrm{m}^{3}$.

The blast wave propagation and its interaction with the surrogate head is a fluid-structure interaction (FSI) problem. The air inside the shock tube was modeled with Eulerian elements and the surrogate head was modeled with Lagrangian elements. The Eulerian domain consisted of 1,378,176 brick elements with approximate mesh refinement near the region of the surrogate head to capture FSI effects. The Eulerian domain of air was chosen as $600 \mathrm{~mm} \times 600 \mathrm{~mm} \times 1200 \mathrm{~mm}$ such that the reflections from domain boundaries were negligible during the $4 \mathrm{~ms}$ simulation time.
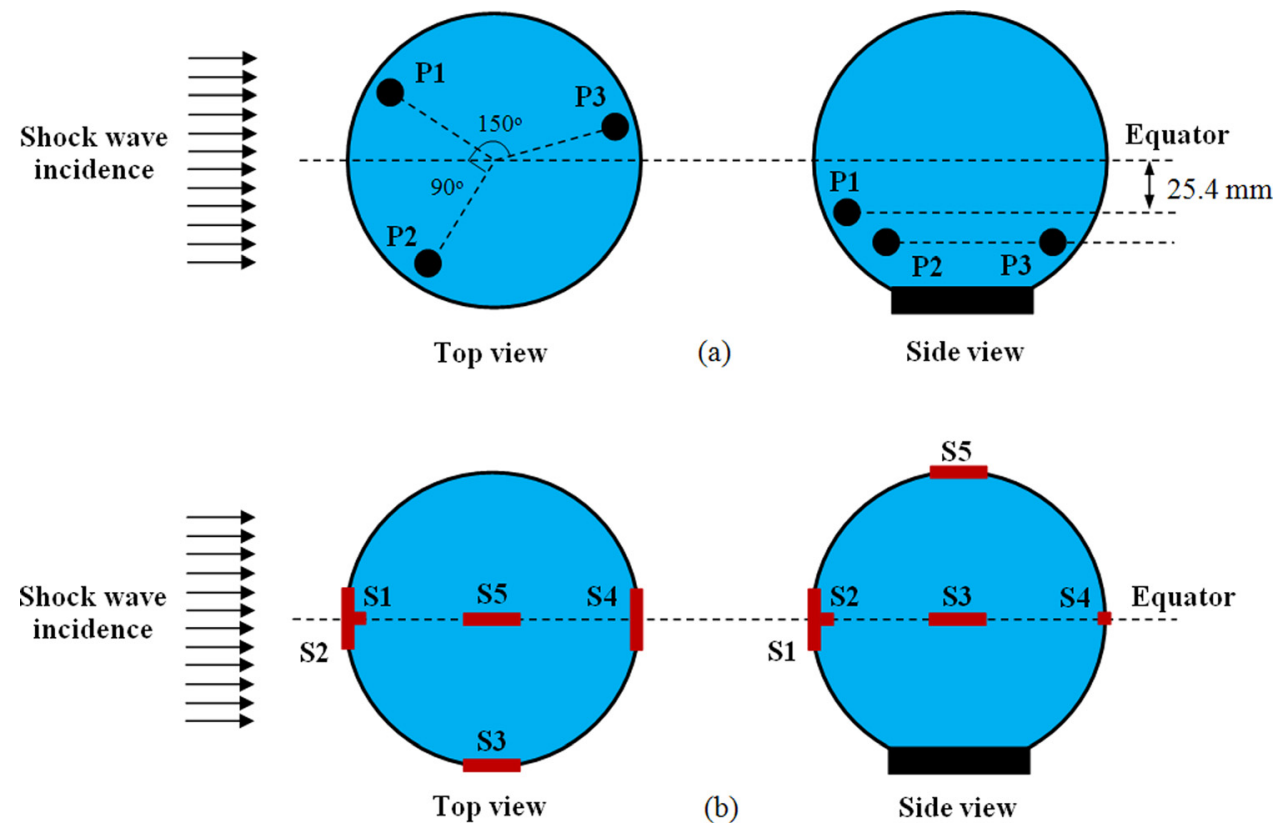

Fig. 2 Locations of (a) pressure sensors in the water and (b) strain gauges on the surface of the polycarbonate shell 


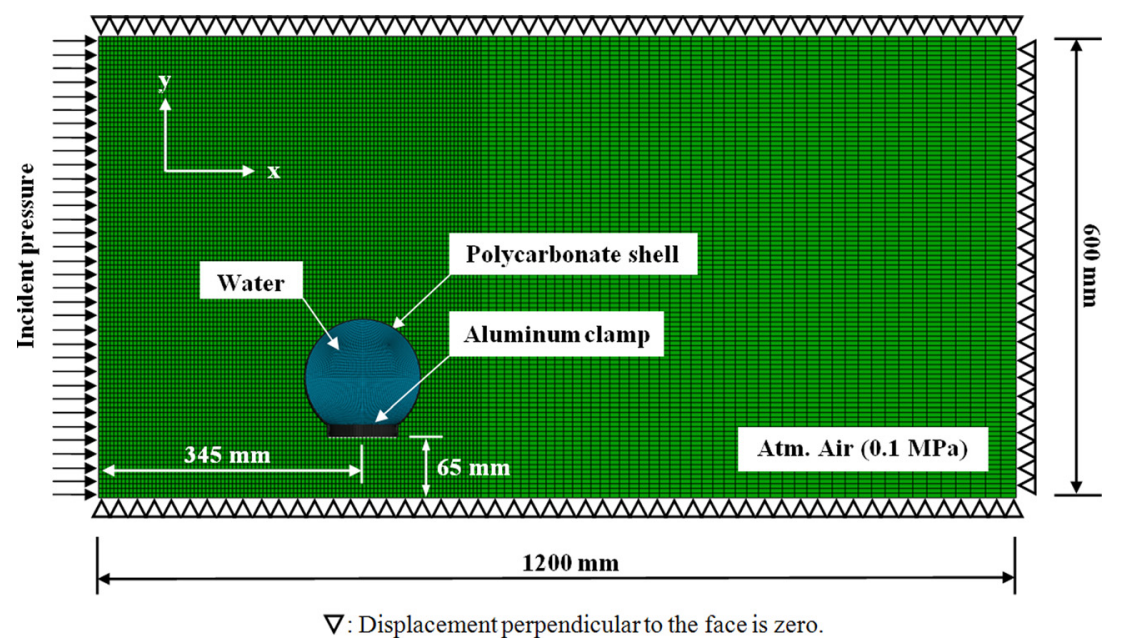

Fig. 4 Finite element model of surrogate head subjected to blast loading (cut view in transverse plane)

Table 2 EOS parameters for both water and air $[9,13,28]$

\begin{tabular}{llc}
\hline \hline Material & \multicolumn{1}{c}{ Parameter } & Value \\
\hline Water & Viscosity $\eta\left(\mathrm{N} . \mathrm{s} / \mathrm{mm}^{2}\right)$ & $1 \times 10^{-8}$ \\
& Sound speed $c_{0}(\mathrm{~mm} / \mathrm{s})$ & $1.45 \times 10^{6}$ \\
& Hugoniot slope coefficient $s(/)$ & 0 \\
& Grüneisen's gamma $\Gamma_{0}(/)$ & 0 \\
\multirow{2}{*}{ Air } & Density $\rho\left(\mathrm{kg} / \mathrm{m}^{3}\right)$ & 1.1607 \\
& Gas constant $R(\mathrm{~J} /(\mathrm{kg}-\mathrm{K}))$ & 287.05 \\
& Temperature $T(\mathrm{~K})$ & 300 \\
\hline \hline
\end{tabular}

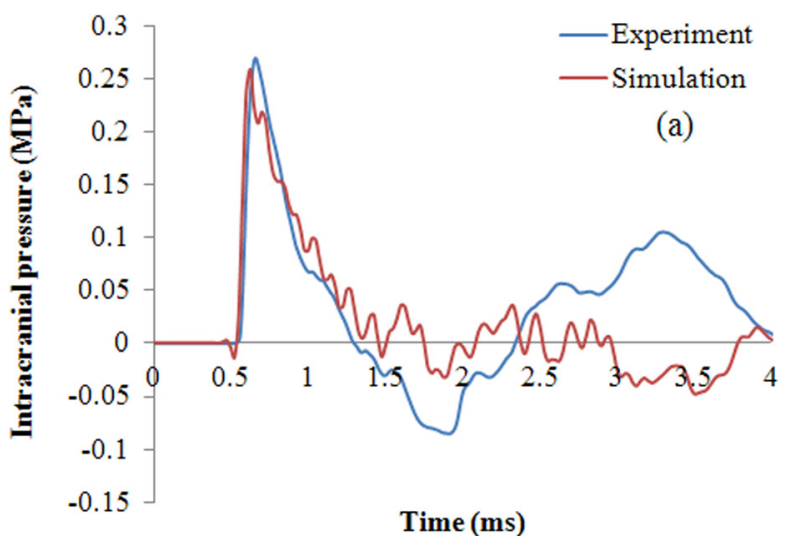

The polycarbonate shell, water, and aluminum clamp were meshed with reduced eight-node hexahedral elements (C3D8R). A mesh convergence test was conducted, resulting in a chosen minimum mesh size of $2 \mathrm{~mm}$.

The measured incident pressure history (Fig. 3) was used as the pressure boundary condition at the inlet of the Eulerian domain. The velocity perpendicular to each face of the Eulerian domain was kept equal to zero to avoid escaping/leaking of air through these faces. This would create a pure 1D shock front traveling in the $x$-direction without lateral flow. The bottom face of the clamp was constrained in all six degrees of freedom. The interaction
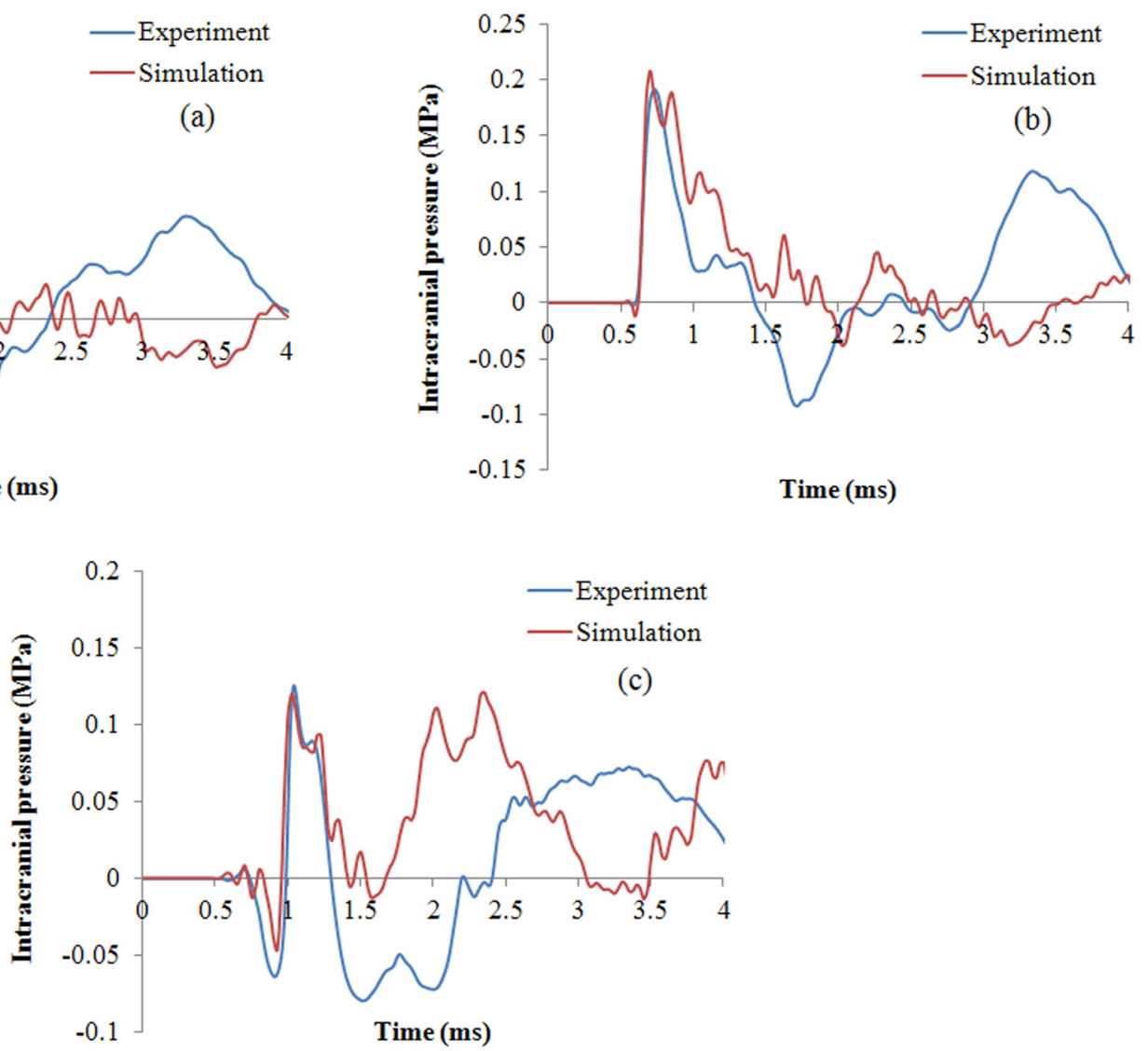

Fig. 5 Experiment and numerical comparison of pressure histories in the brain simulant, i.e., water, at locations: (a) P1, (b) P2, and $(c)$ P3 

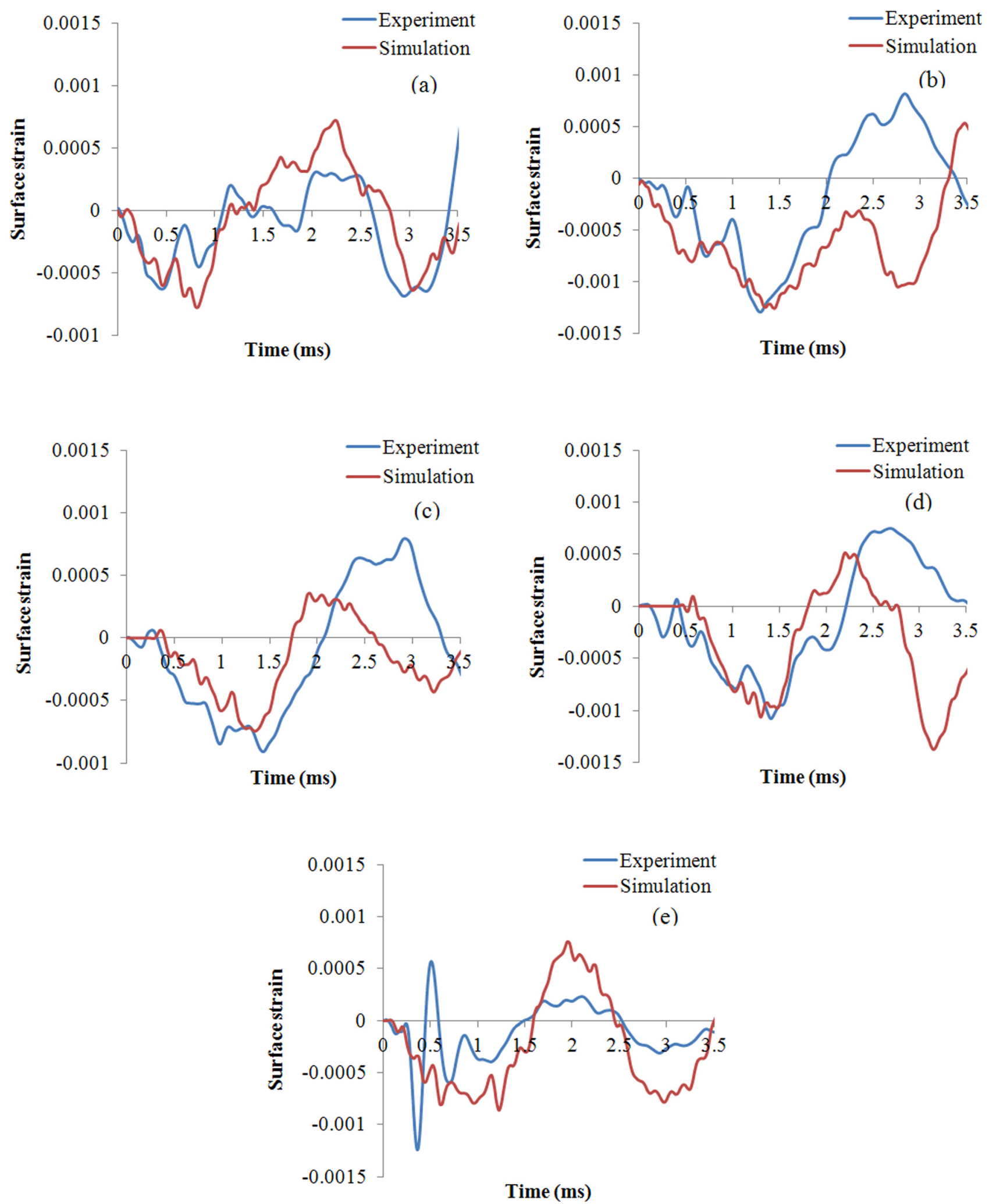

Fig. 6 Experiment and numerical comparison of surface strains on the skull simulant, i.e., the polycarbonate shell, at locations: (a) S1, (b) S2, (c) S3, (d) S4, and (e) S5

between a Eulerian domain and a Lagrangian one was enforced through a penalty contact algorithm with frictionless tangential sliding and hard contact normal behavior. A typical simulation required about $7 \mathrm{~h}$ of central processing unit (CPU) time, running on a Dell T3500 double quad-core Xeon W3550 processor for an integration time of $4 \mathrm{~ms}$.

\section{Comparison Between Shock Tube Tests and Finite Element Results}

The pressure histories in the brain simulant at locations P1, P2, and P3 labeled in Fig. 2(a) were compared between the experimental measurements and numerical results, as shown in 


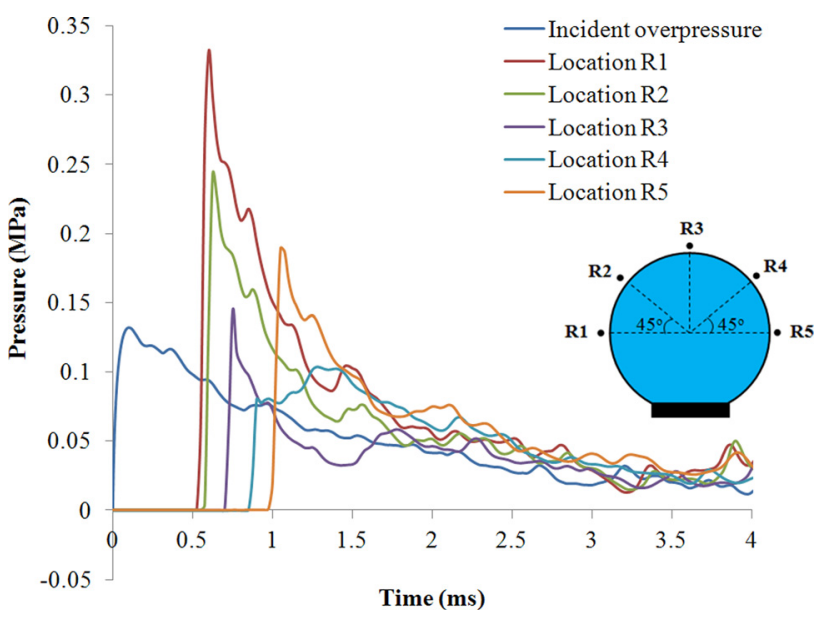

Fig. 7 Reflected pressure histories measured at five locations around the surrogate head

Fig. 5. For easy comparison, the arrival time of the experimentally measured pressure profile was shifted to align with that of the numerical results. It was clear that the major features of the measured pressure profiles, including the peak overpressure, nonlinear decay, and small peaks and valleys were captured by the simulation. For example, considering the peak overpressure, the deviations between experiment and simulation were only $3.75 \%$, $8.31 \%$, and $4.18 \%$ at locations $\mathrm{P} 1, \mathrm{P} 2$, and $\mathrm{P} 3$, respectively. The differences could be explained by the sensitivity of the pressure sensors. Moreover, significant low-frequency oscillation of the pressure magnitude was observed at the end of the decay period (from $2.5 \mathrm{~ms}$ to $4 \mathrm{~ms}$ ) in both experiment and simulation, indicating that complicated wave interactions took place at these locations during this period.

Strain history measurements have seldom been demonstrated in the existing literature. In this work, the surface strains on the skull simulant at five locations ( $\mathrm{S} 1, \mathrm{~S} 2, \mathrm{~S} 3, \mathrm{~S} 4$, and S5 marked in Fig. 2(b)) were compared between the experimental measurements and numerical simulation, as depicted in Fig. 6. The surface strain histories measured at locations $\mathrm{S} 1-\mathrm{S} 4$ from the simulation matched reasonably well with the experiment up to $2 \mathrm{~ms}$; however, a faster decay and a quicker rise time were observed in the simulation after $2 \mathrm{~ms}$. This deviation might be caused by neglecting the viscoelastic material properties of the skull simulant. The numerically obtained surface strain history at location S5 showed a relatively large discrepancy from the measured one. This could be attributed to the nonuniform thickness of the skull simulant as well as a possible air bubble accumulated at the top of the brain simulant. Considering the objective of this work, it is reasonable to state that the numerically obtained surface strains on the skull simulant and pressure histories in the brain simulant correlated well with the experimental measurements. The experimentvalidated model can then be used to inspect various aspects of the mechanisms of blast wave-surrogate head interactions.

\section{Results}

4.1 Interaction Between Blast Wave and Surrogate Head. The blast wave-surrogate head interactions can be studied by monitoring the reflected pressure histories at various locations around the head, as shown in Fig. 7. Five locations from front to back of the head were identified and marked as R1-R5. The incident pressure history has also been included for easy comparison. It was observed that the reflected peak overpressure at location R1 was $0.33 \mathrm{MPa}$. Compared to the incident peak overpressure of $0.13 \mathrm{MPa}$, the reflection factor $\Lambda$, referred to as the ratio of reflected peak overpressure to incident peak overpressure, was calculated as 2.54. As the blast wave traversed the head, the reflected peak overpressure gradually decreased from locations
R1 to R4 and even dropped below the incident peak overpressure at location $\mathrm{R} 4(\Lambda=0.30)$. It should be noted that the reflected peak overpressure measured at location R5 was $0.19 \mathrm{MPa}$ $(\Lambda=1.46)$, which was higher than that of $0.14 \mathrm{MPa}(\Lambda=1.08)$ at location $\mathrm{R} 3$ and $0.10 \mathrm{MPa}(\Lambda=0.30)$ at location $\mathrm{R} 4$.

4.2 Structural Response of the Skull Simulant. The structural response of the skull simulant subjected to blast loading was measured by monitoring the displacement in the transverse plane at various times, as shown in Fig. 8. The motion of the skull simulant was considered inward or outward with respect to its original spherical shape at $t=0 \mathrm{~ms}$. At $t=0.6 \mathrm{~ms}$, the wave front propagated through the ambient air and hit the front region of the skull simulant. The kinetic energy of the reflected pressure was then transmitted to the skull simulant and small localized skull flexure was observed in the front region. At $t=0.75 \mathrm{~ms}$, the stress wave propagated into the central region of the skull simulant, causing the central region to move outward. At $t=1.0 \mathrm{~ms}$, the localized skull flexure in the front region gradually disappeared and it started to move inward at $t=1.87 \mathrm{~ms}$. As time progressed, the central region returned to the equilibrium position at $t=2.0 \mathrm{~ms}$ and then moved inward at $t=2.25 \mathrm{~ms}$. At $t=3.25 \mathrm{~ms}$, the central region moved outward again. Eventually, the entire skull simulant reestablished quasi-equilibrium at $t=4.0 \mathrm{~ms}$.

4.3 Pressure Distributions Inside the Brain Simulant. A typical pressure contour inside the brain simulant is shown in Fig. 9. A clear pressure gradient pattern was observed within the brain simulant, which was qualitatively consistent with the results observed in direct impact events [14]. The peak positive (compressive) pressure occurred at the anterior part (coup site) of the brain simulant and gradually decreased to a negative (tensile) pressure at the posterior part (countercoup site). Figure 10 shows the pressure histories along the centerline of the brain simulant with marked five locations. Pressure history profiles at locations B1 and B5 showed the typical coup-countercoup pattern. The highest peak pressure of $0.32 \mathrm{MPa}$ was observed at location B1, which could be explained by the direct transmission of the blast wave into the brain simulant. The peak pressures decreased to $0.19 \mathrm{MPa}, 0.12 \mathrm{MPa}$, and $0.08 \mathrm{MPa}$ at locations B2, B3, and B4, respectively, whereas it increased to $0.13 \mathrm{MPa}$ at location B5 at the posterior part of the brain. We also noticed a large negative pressure of $-0.07 \mathrm{MPa}$ occurring at location B5 around $1.0 \mathrm{~ms}$.

\section{Discussion}

Blast-induced TBI has stimulated intensive research in recent years to understand its mechanism for better prevention and treatment strategies. A few injury mechanisms have been proposed, including direct cranial transmission [12,15-18], thorax compression $[19,20]$, skull flexure $[8,21]$, rotational/translational acceleration [22-24], and brain cavitation [25,26]. In this work, an experiment-validated numerical model was developed to elucidate the wave transmission mechanism of a head surrogate model (water-filled polycarbonate shell) subjected to blast loading. Repeated shock tube tests were conducted on the surrogate head. The surface strain on the skull simulant and pressure inside the brain simulant were recorded at multiple locations to validate the numerical model. The validated model was then used to inspect more details beyond the experimental measurements such as the flow field around the surrogate head, structural response of the skull simulant, and pressure distributions inside the brain simulant.

As the blast wave encountered the surrogate head, the incident wave pressure was amplified due to the fluid-structure interaction (Fig. 7). This pressure amplification behavior could be attributed to the aerodynamic effects in which the high-velocity particles of the shock front were brought to rest abruptly, leading to an amplified reflected pressure acting on the solid surface of the surrogate head. The initial reflection factor can vary from 2 to 8 , depending 

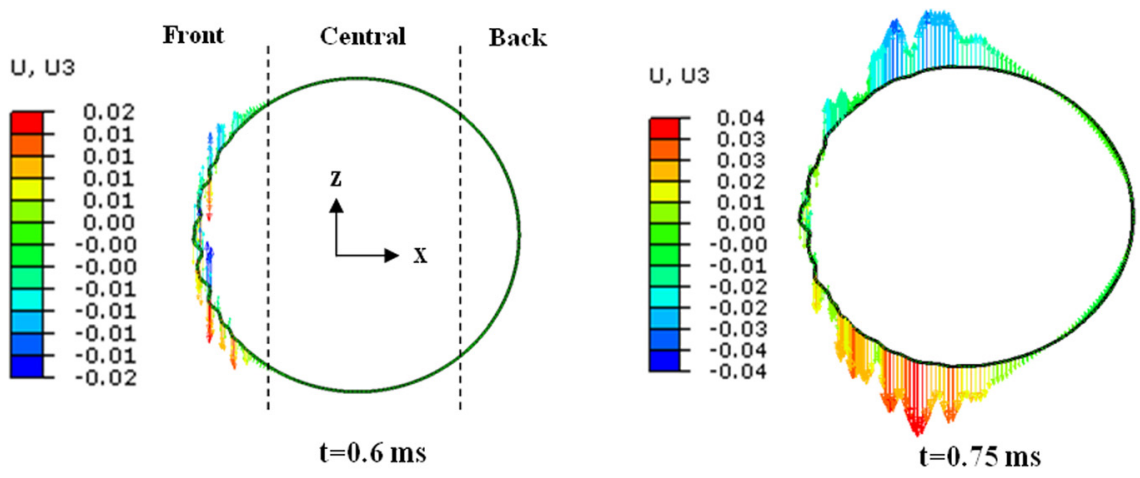

U, บ3
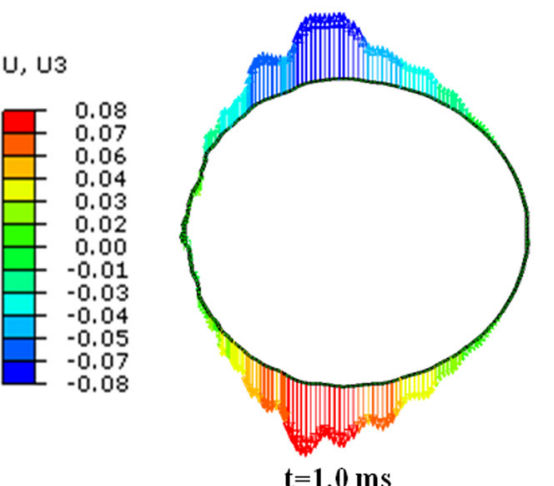

$\mathrm{U}, \mathrm{U3}$
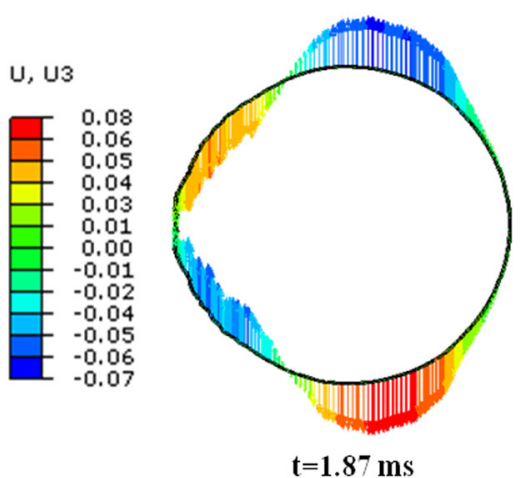

$\mathrm{u}, \mathrm{U3}$
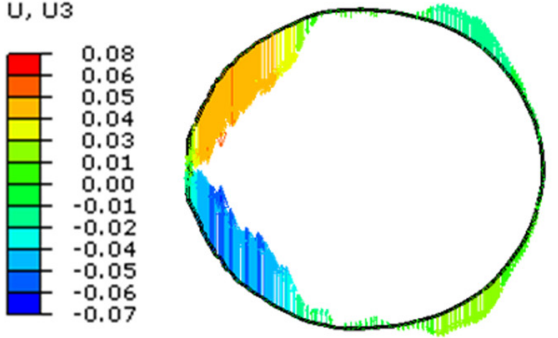

$\mathrm{U}, \mathrm{U3}$
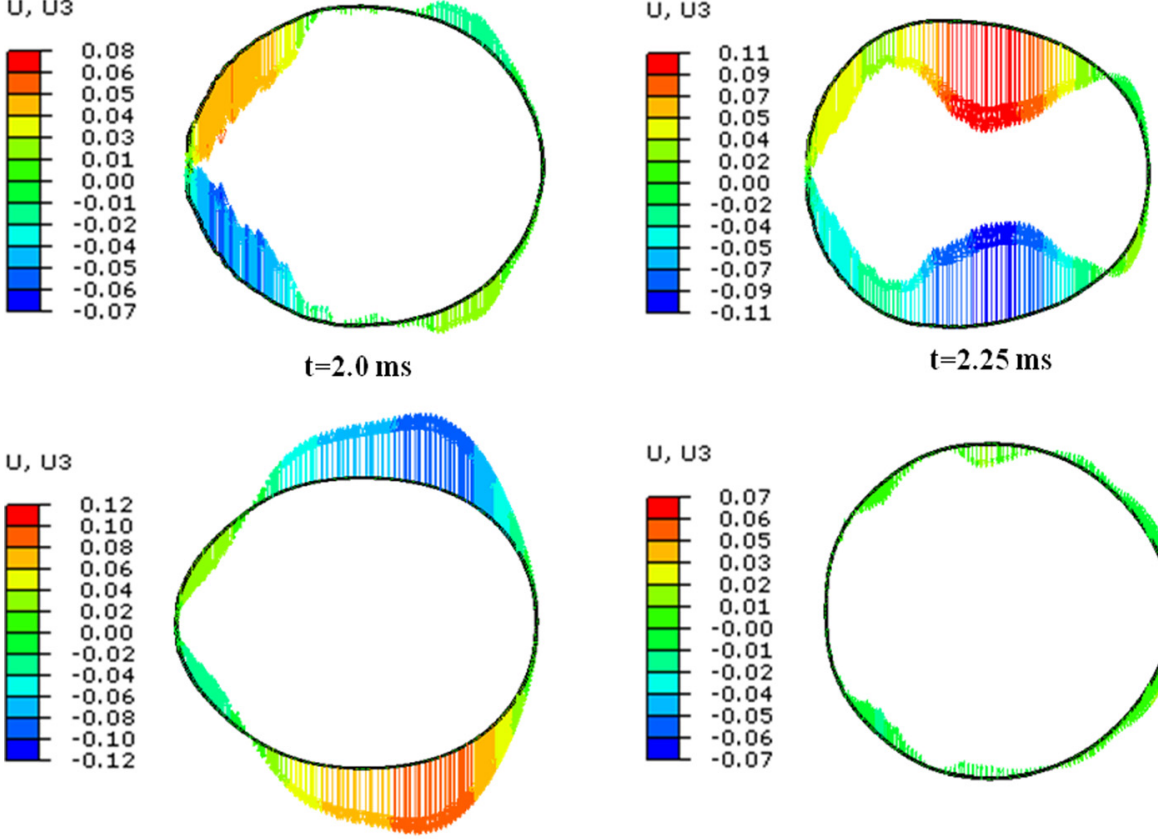

$\mathrm{U}, \mathrm{U} 3$
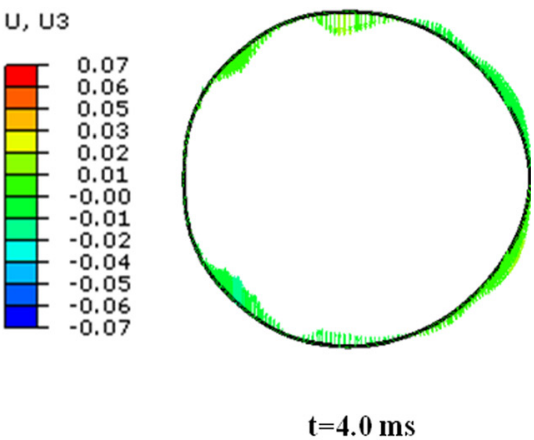

Fig. 8 Spatial and temporal vector plots of the displacement in the transverse plane of the skull simulant (deformation scale factor of 50 )

on several factors such as the incident blast intensity, fluid medium in which blast wave travels, angle of incidence, mass and geometry of the object $[27,28]$. Our results also indicated that the reflected pressure gradually decreased as the blast wave traversed the head $(\Lambda=2.54,1.84,1.08,0.30$ at locations R1, R2, R3, and $\mathrm{R} 4$, respectively) while it increased at the back side of the head ( $\Lambda=1.46$ at location R5). This was due to the fluid dynamics around the surrogate head as demonstrated in Fig. 11, which depicts the flow separation and reattachment in terms of pressure distribution in the vicinity of the surrogate head. It is clear that the reflected pressure at location R1 was substantially higher than the pressure surrounding the head at locations R2 and R3, which drove the flow of air from front to back. The head curvature caused the flow to detach from the head surface at location R3. The incident wave partially diverging away from the head surface contributed to the pressure relief near the surface between locations R3 and R4. The separated blast waves were then joined together behind the head, resulting in an instantaneous pressure increase on the back side of the head (location R5). Our numerical results elucidated the detailed fluid dynamics around the surrogate head, which could be then associated with the structural response of the skull simulant. 


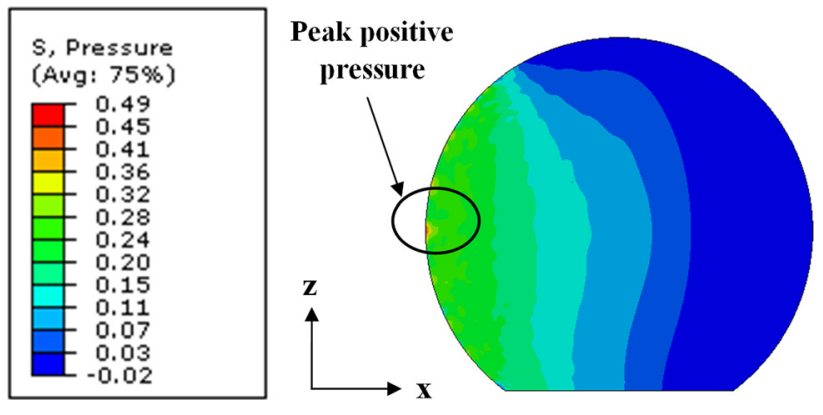

Fig. 9 Typical pressure contour inside the brain simulant at $t=0.625$ ms (unit: MPa)

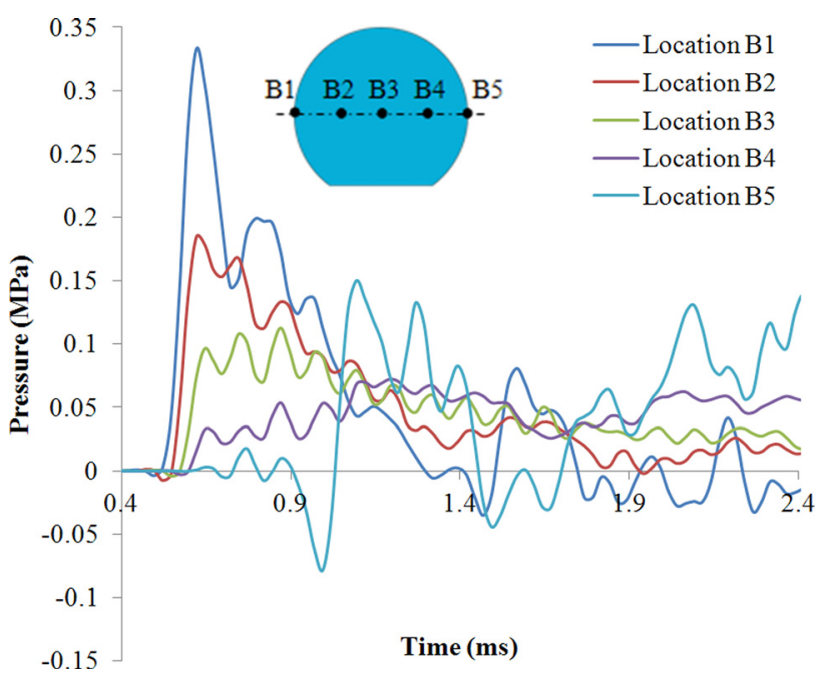

Fig. 10 Pressure histories along the centerline of the brain simulant (cut view in transverse plane)

Blast-induced shape changes of the skull simulant, referred to as skull flexure [21], were clearly illustrated in this work by the displacement vector plots in the transverse plane of the skull simulant (Fig. 8). It clearly demonstrated that the skull simulant oscillated along its longitudinal axis ( $x$-axis). Moss et al. [21] have pointed out that a nonlethal pressure wave could generate flexural ripples in the skull, which could induce damaging intracranial pressure gradients within the brain [8].

To better understand the blast wave transmission mechanism, we have distinguished the stress waves imparted by the skull flexure from the direct blast wave transmission in terms of blast overpressure, surface strain of the skull simulant, and intracranial pressure (Fig. 12). Five marked locations (M1-M5) along the skull to air and brain interfaces were used. The blast overpressure was obtained at the element of the air closest to the skull simulant, the surface strain was measured at the outermost element of the skull simulant, and the intracranial pressure was estimated at the element of the brain simulant closest to the skull simulant. Since the blast overpressure and intracranial pressure had a higher-order magnitude than the surface strain of the skull simulant, biaxial coordinates are used. At location M1, a sharp rise was observed in the intracranial pressure profile, which was in agreement with both profiles of the surface strain and blast overpressure. Following this sharp rise, the intracranial pressure profile closely followed the profile of the blast overpressure throughout the simulation time period ( $4 \mathrm{~ms}$ ). Similarly at location M2, the intracranial pressure profile approximately followed the profile of the blast overpressure. Since the intracranial pressure profiles at locations M1 and M2 followed the profile of the blast overpressure rather than that of the surface strain, it can be inferred that the intracranial pressures in the anterior part of the head were dominated by the direct blast wave propagation, instead of the structural changes in the skull simulant. At locations M3, M4, and M5 of the posterior part of the head, the intracranial pressure profiles could be divided into two regimes. In the first regime (up to $1.2 \mathrm{~ms}$ ), the intracranial pressure profiles followed the sharp rise and quick decay of the blast overpressure profiles. In the second regime (after $1.2 \mathrm{~ms}$ ), the intracranial pressure profiles changed to follow the oscillation of the surface strain profiles. These observations indicated that the intracranial pressure in the posterior part of the head was initiated by the direct blast wave propagation while the stress wave generated by the skull flexure would take effect at a later time. The knowledge of these detailed wave transmission physics at the skull to air and brain interfaces may facilitate developing effective strategies to reduce the occurrence of TBI.

Our results also showed a clear pressure gradient pattern within the brain simulant (Fig. 9). The highest peak pressure occurred at the anterior location $\mathrm{B} 1(0.32 \mathrm{MPa})$, followed by that at location B2 (0.19 MPa), location B3 (0.12 MPa), and location B4 $(0.08 \mathrm{MPa})$, while it increased at the posterior location B5 $(0.13 \mathrm{MPa})$ This order was also observed by Zhu et al. [12]. Moreover, we also observed that a large negative pressure of $-0.07 \mathrm{MPa}$ occurred at the posterior location B5 around $1.0 \mathrm{~ms}$, which was smaller than the reported cavitation pressure criterion of $-0.1 \mathrm{MPa}$ [29]. This indicated that no cavitation existed in our testing conditions. It should be mentioned though that the vulnerable cavitation area located at the posterior part of the head is consistent with the existing publications related to impact- or blast-induced brain injury [26,30,31].

It should be noted that the surrogate design in this study do not reflect all the attributes of the human head. The geometries and material properties of the skull and brain were simplified. Although anatomically detailed human head models [32,33] could provide better predictions of brain dynamics, these models have been rarely validated by experiments under blast scenarios. Even though human brain is $70-80 \%$ percent water, however, the
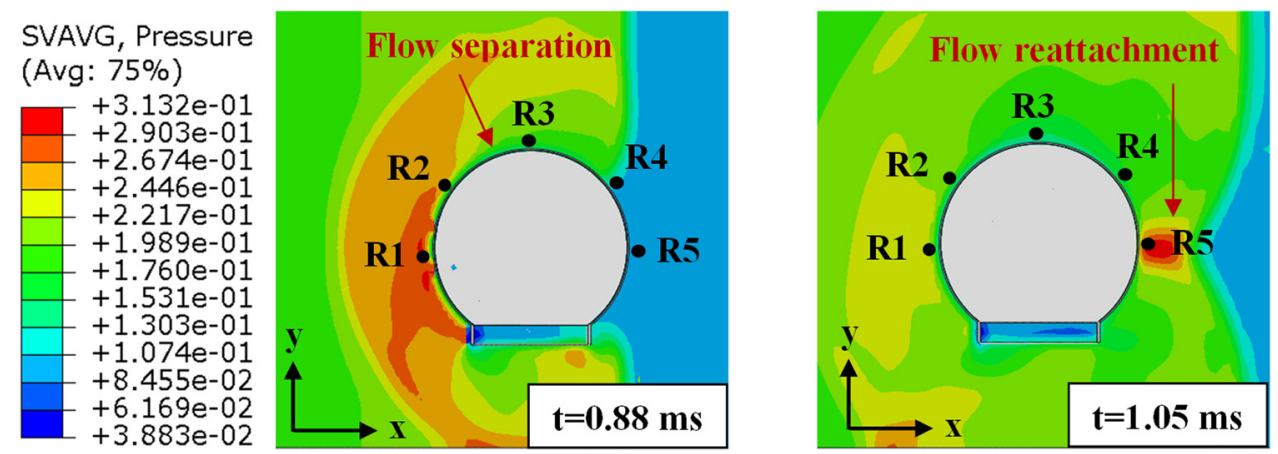

Fig. 11 Pressure distribution in the vicinity of the surrogate head: (a) flow separation at $t=0.88 \mathrm{~ms}$, and $(b)$ flow reattachment at $t=1.05 \mathrm{~ms}$ 

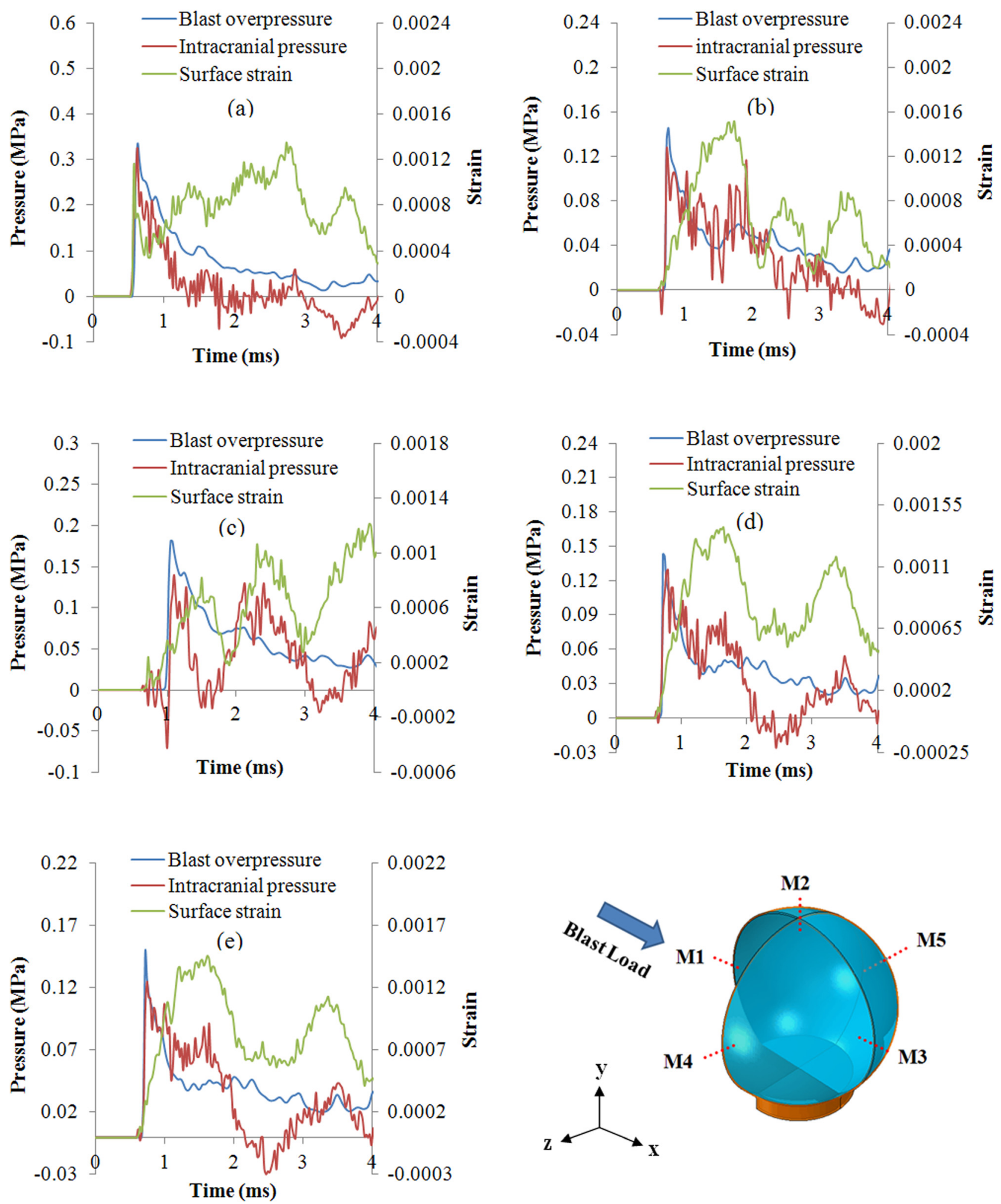

Fig. 12 Blast overpressure, surface strain, and intracranial pressure at five marked locations (a) M1, (b) M2, (c) M3, (d) M4, and (e) M5

neuronal cells, glial cells, axons, vessels, etc. all together make the brain tissue demonstrate viscoelastic, nonlinear, anisotropic properties, which need to be considered in the future head model for evaluating the injury threshold. More realistic models considering patient-specific geometry and hyperplastic and viscoelastic properties of the head will change the spatial and temporal pres- sure profiles within the brain. Despite these simplifications, the present work demonstrated the detailed physics of blast-head interaction. We have developed an experiment-validated numerical model to understand the wave transmission physics, including the flow field around the head, structural response of the skull simulant, and pressure distributions inside the brain simulant. The 
computational tool validated in this work could be extended to more realistic geometry and material characterizations, which may have significant clinical implications for TBI by providing guidance for optimizing protective armors and illuminating the possibilities for exploiting their potential to prevent TBI.

\section{Acknowledgment}

The authors gratefully acknowledge financial support under the U.S. Army Research Office project "Army-UNL Center for Trauma Mechanics" (Contact No. W911NF-08-10483).

\section{References}

[1] Warden, D., 2006, "Military TBI During the Iraq and Afghanistan Wars," J. Head Trauma Rehab., 21(5), pp. 398-402.

[2] Ender, M. G., 2010, "Invisible Wounds of War: Psychological and Cognitive Injuries, Their Consequences, and Services to Assist Recovery," Contemp. Sociol., 39(4), pp. 399-402.

[3] Marshall, K. R., Holland, S. L., Meyer, K. S., Martin, E. M., Wilmore, M., and Grimes, J. B., Mild Traumatic Brain Injury Screening, Diagnosis, and Treatment," Mil. Med., 177(8 Suppl), pp. 67-75.

[4] Long, J. B., Bentley, T. L., Wessner, K. A., Cerone, C., Sweeney, S., and Bauman, R. A., 2009, "Blast Overpressure in Rats: Recreating a Battlefield Injury in the Laboratory," J. Neurotraum., 26(6), pp. 827-840.

[5] Cheng, J. M., Gu, J. W., Ma, Y. A., Yang, T., Kuang, Y. Q., Li, B. C. and Kang, J. Y., 2010, "Development of a Rat Model for Studying Blast-Induced Traumatic Brain Injury," J. Neurol. Sci., 294(1-2), pp. 23-28.

[6] Risling, M., Plantman, S., Angeria, M., Rostami, E., Bellander, B. M., Kirkegaard, M., Arborelius, U., and Davidsson, J., 2011, "Mechanisms of Blast Induced Brain Injuries, Experimental Studies in Rats," Neuroimage, 54, pp. S89-S97.

[7] Saljo, A., Mayorga, M., Bolouri, H., Svensson, B., and Hamberger, A., 2011 "Mechanisms and Pathophysiology of the Low-Level Blast Brain Injury in Animal Models," Neuroimage, 54, pp. S83-S88.

[8] Bolander, R., Mathie, B., Bir, C., Ritzel, D., and Vandevord, P., 2011, "Skull Flexure as a Contributing Factor in the Mechanism of Injury in the Rat When Exposed to a Shock Wave," Ann. Biomed. Eng., 39(10), pp. 2550-2559.

[9] Sundaramurthy, A., Alai, A., Ganpule, S., Holmberg, A., Plougonven, E., and Chandra, N., 2012, "Blast-Induced Biomechanical Loading of the Rat: An Experimental and Anatomically Accurate Computational Blast Injury Model," J. Neurotram., 29(13), pp. 2352-2364.

[10] Alley, M. D., Schimizze, B. R., and Son, S. F., 2011, "Experimental Modeling of Explosive Blast-Related Traumatic Brain Injuries," Neuroimage, 54, pp. S45-S54.

[11] Ganpule, S., Alai, A., Plougonven, E., and Chandra, N., 2012, "Mechanics of Blast Loading on the Head Models in the Study of Traumatic Brain Injury Using Experimental and Computational Approaches," Biomech. Model. Mech., 12(3), pp. 511-531.

[12] Zhu, F., Wagner, C., Dal Cengio Leonardi, A., Jin, X., VandeVord, P., Chou, C., Yang, K. H., and King, A. I., 2012, "Using a Gel/Plastic Surrogate to Study the Biomechanical Response of the Head Under Air Shock Loading: a Combined Experimental and Numerical Investigation," Biomech. Model Mech. 11(3), pp. 341-353.

[13] Liu, M. B., Liu, G. R., and Lam, K. Y., 2002, "Investigations Into Water Mitigation Using a Meshless Particle Method," Shock Waves, 12(3), pp. 181-195.

[14] Chen, Y., and Ostoja-Starzewski, M., 2010, "MRI-Based Finite Element Modeling of Head Trauma: Spherically Focusing Shear Waves," Acta Mech., 213(1-2), pp. 155-167.

[15] Bauman, R. A., Ling, G., Tong, L., Januszkiewicz, A., Agoston, D., Delanerolle, N., Kim, Y., Ritzel, D., Bell, R., and Ecklund, J., 2009, "An Introductory Characterization of a Combat-Casualty-Care Relevant Swine Model of Closed
Head Injury Resulting From Exposure to Explosive Blast," J. Neurotram., 26(6), pp. 841-860

[16] Chavko, M., Koller, W. A., Prusaczyk, W. K., and McCarron, R. M., 2007, "Measurement of Blast Wave by a Miniature Fiber Optic Pressure Transducer in the Rat Brain," J. Neurosci. Meth., 159(2), pp. 277-281.

[17] Chavko, M., Watanabe, T., Adeeb, S., Lankasky, J., Ahlers, S. T., and McCarron, R. M., 2011, "Relationship Between Orientation to a Blast and Pressure Wave Propagation Inside the Rat Brain," J. Neurosci. Meth., 195(1), pp. 61-66.

[18] Nyein, M. K., Jason, A. M., Yu, L., Pita, C. M., Joannopoulos, J. D., Moore, D. F., and Radovitzky, R. A., 2010, "In Silico Investigation of Intracranial Blast Mitigation With Relevance to Military Traumatic Brain Injury," Proc. Natl. Acad. Sci. USA, 107(48), pp. 20703-20708.

[19] Bhattacharjee, Y., 2008, "Neuroscience-Shell Shock Revisited: Solving the Puzzle of Blast Trauma," Science, 319(5862), pp. 406-408.

[20] Courtney, A. C., and Courtney, M. W., 2009, "A Thoracic Mechanism of Mild Traumatic Brain Injury due to Blast Pressure Waves," Med. Hypotheses, 72(1), pp. $76-83$.

[21] Moss, W. C., King, M. J., and Blackman, E. G., 2009, "Skull Flexure From Blast Waves: A Mechanism for Brain Injury With Implications for Helmet Design," Phys. Rev. Lett., 103(10), pp. 1-4.

[22] Finkel, M. F., 2006, "The Neurological Consequences of Explosives," J. Neurol. Sci., 249(1), pp. 63-67.

[23] Krave, U., Hojer, S., and Hansson, H. A., 2005, "Transient, Powerful Pressures Are Generated in the Brain by a Rotational Acceleration Impulse to the Head," Eur. J. Neurosci., 21(10), pp. 2876-2882.

[24] Zhang, L., Yang, K. H., and King, A. I., 2004, "A Proposed Injury Threshold for Mild Traumatic Brain Injury," ASME J. Biomech. Eng., 126(2), pp. 226-236.

[25] Nakagawa, A., Fujimura, M., Kato, K., Okuyama, H., Hashimoto, T., Takayama, K., and Tominaga, T., 2009, "Shock Wave-Induced Brain Injury in Rat: Novel Traumatic Brain Injury Animal Model," Acta Neurochirurgica Suppl., 102, pp. 421-424.

[26] Goeller, J., Wardlaw, A., Treichler, D., O’Bruba, J., and Weiss, G., 2012, "Investigation of Cavitation as a Possible Damage Mechanism in Blast-Induced Traumatic Brain Injury,” J. Neurotram., 29(10), pp. 1970-1981.

[27] Anderson, J. D., 2001, Fundamentals of Aerodynamics, McGraw-Hill, New York.

[28] Ganpule, S., Gu, L., Alai, A., and Chandra, N., 2012, "Role of Helmet in the Mechanics of Shock Wave Propagation Under Blast Loading Conditions," Comput. Meth. Biomech. Biomed. Eng., 15(11), pp. 1233-1244.

[29] Lubock, P., and Goldsmith, W., 1980, "Experimental Cavitation Studies in a Model Head-Neck System," J. Biomech., 13(12), pp. 1041-1052.

[30] Marklund, N., Clausen, F., Lewen, A., Hovda, D. A., Olsson, Y., and Hillered, L., 2001, "Alpha-phenyl-tert-N-butyl nitrone (PBN) Improves Functional and Morphological Outcome After Cortical Contusion Injury in the Rat," Acta Neurochir., 143(1), pp. 73-81.

[31] Nakagawa, A., Fujimura, M., Kato, K., Okuyama, H., Hashimoto, T. Takayama, K., and Tominaga, T., 2009, "Shock Wave-Induced Brain Injury in Rat: Novel Traumatic Brain Injury Animal Model," Acta Neurochirurgica Suppl., 102, pp. 421-424.

[32] Mao, H. J., Zhang, L. Y., Jiang, B. H., Genthikatti, V. V., Jin, X., Zhu, F., Makwana, R., Gill, A., Jandir, G., Singh, A., and Yang, K. H., 2013, "Development of a Finite Element Human Head Model Partially Validated With Thirty Five Experimental Cases," ASME J. Biomech. Eng., 135(11), p. 111002.

[33] Willinger, R., Kang, H.-S., and Diaw, B., 1999, "Three-Dimensional Human Head Finite-Element Model Validation Against Two Experimental Impacts," Ann. Biomed. Eng., 27(3), pp. 403-410.

[34] Taylor, P. A., and Ford, C. C., 2009, "Simulation of Blast-Induced Early-Time Intracranial Wave Physics Leading to Traumatic Brain Injury," ASME J. Biomech. Eng., 131(6), p. 061007.

[35] Kleinschmit, N. N., 2011, "A Shock Tube Technique for Blast Wave Simulation and Studies of Flow Structure Interactions in Shock tube Blast Experiments," Master thesis, University of Nebraska-Lincoln, Lincoln, NE. 